\title{
PERI-URBAN RESIDENTIAL NEIGHBOURHOODS AT THE MARGINS OF CURRENT TRENDS IN URBAN GROWTH: TOWARDS SUSTAINABLE TRANSITION PATHS?
}

\author{
JUDITH DROUILLES, SOPHIE LUFKIN \& EMMANUEL REY \\ Laboratory of Architecture and Sustainable Technologies (LAST), Ecole Polytechnique \\ Fédérale de Lausanne, Switzerland.
}

\begin{abstract}
In Switzerland as in most European countries, the last decades of urban development have put much pressure on the environment due to uncontrolled urban sprawl. The existing peripheral residential built-up areas mostly composed of single-family houses are responsible for and subjected to many sustainability issues, which are expected to grow in the short/medium term. Focusing on urban and architectural design, this on-going research investigates possible paths for the future of peri-urban neighbourhoods of single-family houses by 2050 . The paper presents the intermediary results of several test-applications of prospective scenarios developed for two case studies in the urban region of Lausanne, Switzerland. First, this article briefly introduces the research framework of the periurban question in Switzerland by highlighting the specificities of the policy and territorial contexts. Second, it describes the design framework, focusing on the elaboration of a typology of peri-urban neighbourhoods of single-family houses used as a preoperational tool to guide the design process. The core of the paper then focuses on the conceptual elaboration of four prospective scenarios foreseeing possible evolutions for peri-urban neighbourhoods of single-family houses. To illustrate this approach, test-applications - in terms of urban and architectural design - are conducted in two existing neighbourhoods. Finally, a limited list of indicators on density, land use and environmental impacts helps assessing the performances of each applied prospective scenario. The scenarios seek to be operational and feasible in a way to provide a decision support. The preliminary conclusions of the study highlight several initial conditions to bring peri-urban neighbourhoods on a path towards sustainability transitions.

Keywords: assessment, design, Peri-urban, prospective scenario, sustainability transition.
\end{abstract}

\section{INTRODUCTION}

Nowadays, most current practices in urban growth follow two major paths: the first one considers the urban renewal of well-connected built-up areas [1], while the second focuses on urban fringes and investigates the possibility of new sustainable developments [2]. In Switzerland, the recent revision of the law on territorial planning has instigated a differential treatment between compact built-up areas and dispersed peripheral sectors [3]: in well-connected urban areas, densification strategies seek to optimize land-use and increase dwelling stock, while in peripheral areas the policy framework constraints new developments and limits urban sprawl to preserved soils and landscapes. In this context, very little space remains for the redefinition of existing peripheral residential neighbourhoods, which result from urban sprawl and are badly connected to public transport and services networks

In response, the on-going research project Living peripheries develops a prospective approach on the question of sustainability transitions of peri-urban neighbourhoods of single-family houses in Switzerland. It follows a research by design method, where, based on a theoretical model, urban and architectural design provides a way of collecting data and experimenting research hypothesis. Once the research object has been delimitated, the method relies on five steps: 
1. Definition of the research framework related to policy and territorial contexts;

2. Definition of the design framework based on elaborating a typology of neighbourhoods of single-family houses as a pre-operational tool;

3. Conceptual elaboration of four prospective scenarios foreseeing evolutions of peri-urban neighbourhoods of single-family houses by 2050 ;

4. Test-application through design of the prospective scenarios on selected case studies;

5. Assessment of the designs in the scope of sustainability.

The paper follows the same structure. It emphasizes steps 3 to 5, which, to date, have not been published $[4,5]$. First, it introduces the current evolution of the Swiss policy framework, the impact on future urban growth and the topic of peri-urban areas. Second, it describes the typology of peri-urban neighbourhoods of single-family houses and its use as framework for the design process. Third, it presents four prospective scenarios for peri-urban neighbourhoods of single-family houses, based on findings from a series of interviews conducted with urban-planning and architecture experts. Forth, within two selected case studies, the paper proposes a preliminary test-application of the four prospective scenarios. Fifth, a brief assessment compares trends and performances in terms of sustainability achieved through design.

\section{POLICY AND TERRITORIAL CONTEXTS}

\subsection{Policy framework evolution}

Recent evolutions of the policy framework, in particular the revision of the law on territorial planning (LTP), aim at slowing down urban sprawl [3]. The law relies on prospective territorial diagnostics and stipulates that new development planning must not exceed the housing needs of the next fifteen years. Main principles proceed from Federal level while precise application tools and guidelines come from each Canton through their local planning document. In Canton of Vaud, where the research is conducted, LTP's principles are translated into two elements:

1. the definition of a municipal demographic growth regulation, through an annual growth rate and a maximum population reached by 2036 ;

2. the definition of a minimal built density of 0.4 for all new developments [6].

The cantonal planning document expresses those guidelines with the aim of intensifying the hierarchy between municipalities based on a network of centres. To do so, growth rates are specified according to the pertaining or not to a "central area" and based on a prospective study of demographic growth in the Canton by 2040 [7]. The pending presentation of specific case studies will illustrate the direct policy impacts on actual future population growth potential.

\subsection{Peri-urban residential municipalities}

Official institutions such as the Swiss Federal Statistical Office (FSO) [8] are constantly updating the classification of urban spaces and delimitation of urban regions to follow up on the changes implied by metropolization [1]. Consequently, we witness the expansion of peripheral areas under functional influence of a main city (daily commuting). The term 
"peri-urban" is commonly used to qualify this great variety of areas, from housing neighbourhoods to agricultural or industrial sectors [6]. Facing these limitations in the definition of the notion "peri-urban", we have elaborated a subcategory of municipalities among FSO's categorization of "spaces with urban character" [8]: the "peri-urban residential municipalities" [5]. It allows focusing on peripheral municipalities under higher urban influence, with significant residential character, and therefore more representative of the phenomenon of urban sprawl behind the exponential development of individual housing in peri-urban areas [10].

\section{NEIGHBOURHOOD TYPOLOGY AS DESIGN FRAMEWORK}

Documenting neighbourhoods of single-family houses and building a preoperational tool stand at the interface of the territorial analysis and the design process. This tool, presented in a previous article [4], is a typology of peri-urban neighbourhoods of single-family houses that delimitates significant categories and sets initial guidelines to orient design decisions $[5,11]$. The analysis is conducted in the urban region of Lausanne, which was selected as one of the most representative of the peri-urban phenomenon in Switzerland. In addition, it has the unique feature of developing among a single Canton, thus leaving aside the complex issue of inter-cantonal coordination.

The typology relies on three guiding discriminatory criteria:

1. Distance to the train station, 0-1 kilometre; more than 1 kilometre [12].

2. Main construction period: 1950-1976 or 1976-2000 [13].

3. Neighbourhood size: $0.5-5$ hectares, more than 5 hectares.

Five types emerge from the observation and listing of about hundred thirty neighbourhoods (Table 1). In the framework of this paper, two representative neighbourhoods belonging to two types showing opposite features were selected to conduct test-applications: Type 1 (Chavornay) (Fig. 1c) and Type 4 (Savigny) (Fig. 1d).

Chavornay and Savigny are two peri-urban residential municipalities of the urban region of Lausanne (Fig. 1a). In 2015, Chavornay had a population of 4'050 inhabitants, and Savigny 3'304 [14]. According to the cantonal planning document, a maximum growth of 1'442 inhabitants by 2036 is allowed in Chavornay, while it is limited to 702 inhabitants in Savigny. The growth potential is different between each municipality because it depends on the proportion of the population located within the central area, which bears a higher annual growth rate of $1.7 \%$ instead of $0.75 \%$ in the rest of the municipality. In Chavornay, $91 \%$ of the population lives in the central area, as opposed to $29 \%$ in Savigny, characterized by a much more dispersed urbanisation (Fig. 1b).

Table 1: Typology of peri-urban neighbourhoods of single-family houses in Lausanne: classification criteria

\begin{tabular}{|c|c|c|c|c|c|}
\hline Criteria & Type 1 & Type 2 & Type 3 & Type 4 & Type 5 \\
\hline Distance to train station & \multicolumn{2}{|c|}{$<1 \mathrm{~km}$} & \multicolumn{2}{|c|}{$>1 \mathrm{~km}$} & $>1 \mathrm{~km}$ \\
\hline Main construction period & \multicolumn{2}{|c|}{ 1950-1976 } & \multicolumn{2}{|c|}{ 1950-1976 } & 1976-2000 \\
\hline Neighbourhood size & $>5$ ha & $0.5-5$ ha & $>5$ ha & $0.5-5$ ha & $0.5-5$ ha \\
\hline
\end{tabular}


(a)

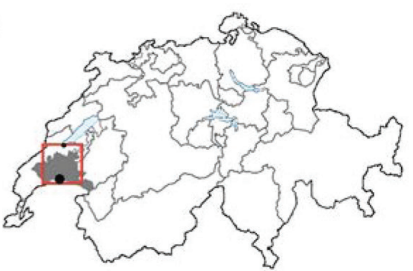

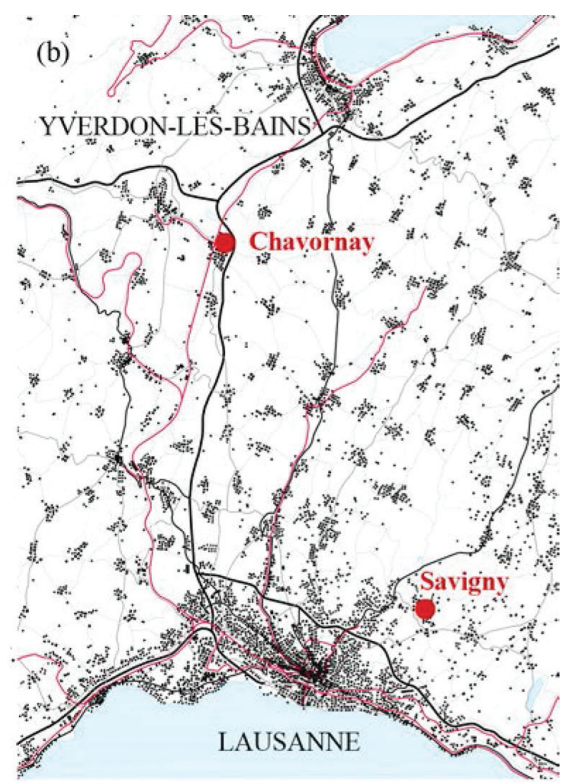

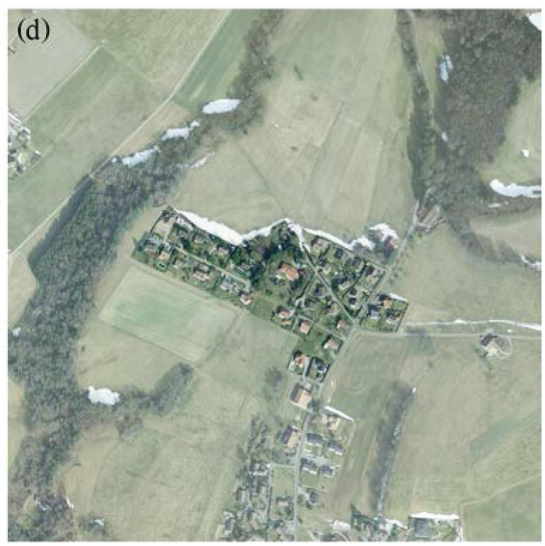

Figure 1: (a) Urban region of Lausane, Switzerland. (b) Location of two case studies (Type 1 - Chavornay, Type 4 - Savigny) in the urban region of Lausanne, (block: roads, red: railway). (c) Type 1: reighbourhood in Chavornay. 800m 800m. 89,910 $\mathrm{m}^{2} 93$ dwellings. 254 inhabitants. (d) Type 4: neighbourhood in Savigny. 800m 800m $48,740 \mathrm{~m}^{2} .34$ dwellings. 101 inhabitants. (Source Swisstopo 2015)

\section{PROSPECTIVE SCENARIOS}

Embedded within this policy and territorial context, the research aims at developing several prospective design scenarios for 2050 to investigate possible transition paths for the periurban neighbourhoods of single-family houses. A more detailed explanation of the methodology used for the elaboration of the theoretical prospective scenario was presented in a previous paper [5]. The foundations consist in a literature review on future societal evolutions in Switzerland and other post-industrial European countries. Preliminary propositions were tested with a panel of fifteen experts in the fields of architecture or urban and territorial planning. Interviews conducted in winter 2016-2017 gave us insights into operational and 
feasible propositions for the future of neighbourhood of single-family houses whose evolution is much limited both by the legal framework (revision of the LTP) and by individual property constraints. In that sense, the proposed evolutions must be fair and acceptable for each individual owner affected by the transformations, while they also cultivate the ambition to go beyond current renovation practices, which are often limited to soft-densification mechanisms developed at the scale of a single house or plot $[15,16]$.

Figure 2 presents all four theoretical prospective scenarios investigating future transition paths for 2050, based on E0: state in 2015 used as baseline. Scenarios S1 - Exclusivity and S2 - Opportunity rely on current trends and propose evolutions at the scale of each house and plot without reconfiguration of land tenure. $S 1$ relies on the preservation of current living environment and way of life. In $S 2$, private economic interest leads evolutions and needs. Scenarios S3 - Urbanity and S4 - Mutuality consist on the other hand in a municipal planning at the scale

E0: Neighbourhood in 2015

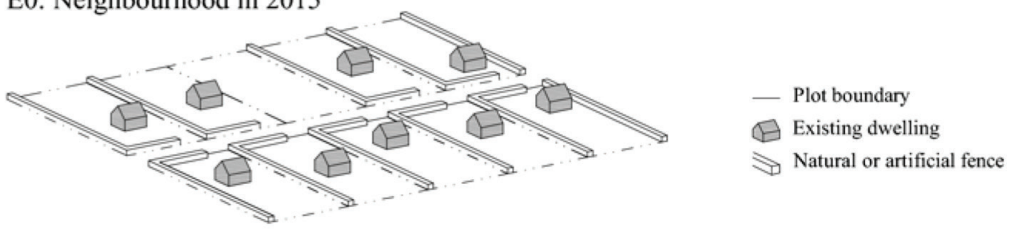

S1: Exclusivity
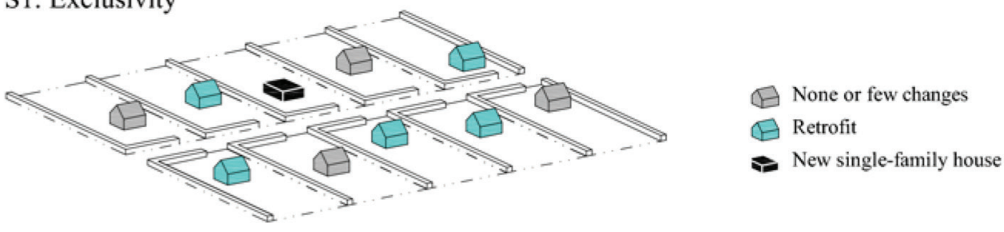

S2: Opportunity
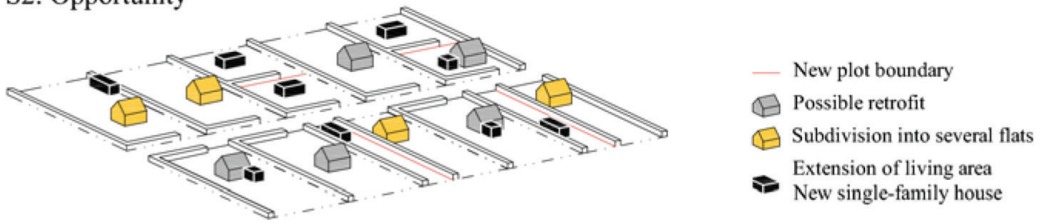

S3: Urbanity

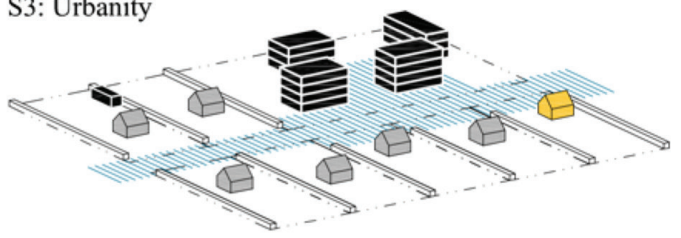

Main evolution (90\%)

F Mixed-use building

Public spaces

Soft mobility, public and/or shared

Secondary evolution $(10 \%)$

$\boxminus$ Possible retrofit

$\otimes$ Subdivision into several flats

Extension of living area

New single-family house

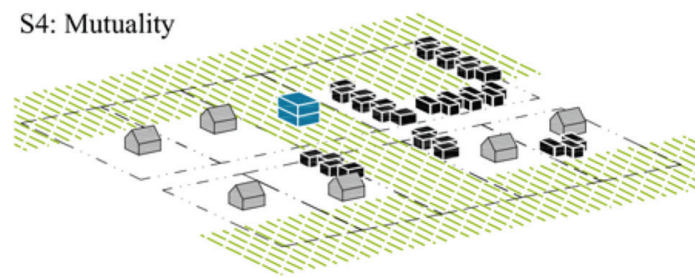

\footnotetext{
New single-family house

Dense individual housing

IE Community centre

Shared, mixed-use space

Landscape integration

$\triangle$ Possible retrofit
}

Figure 2: Four theoretical prospective scenarios investogating future transitions for the periurban neighbourhoods of single-family houses. 


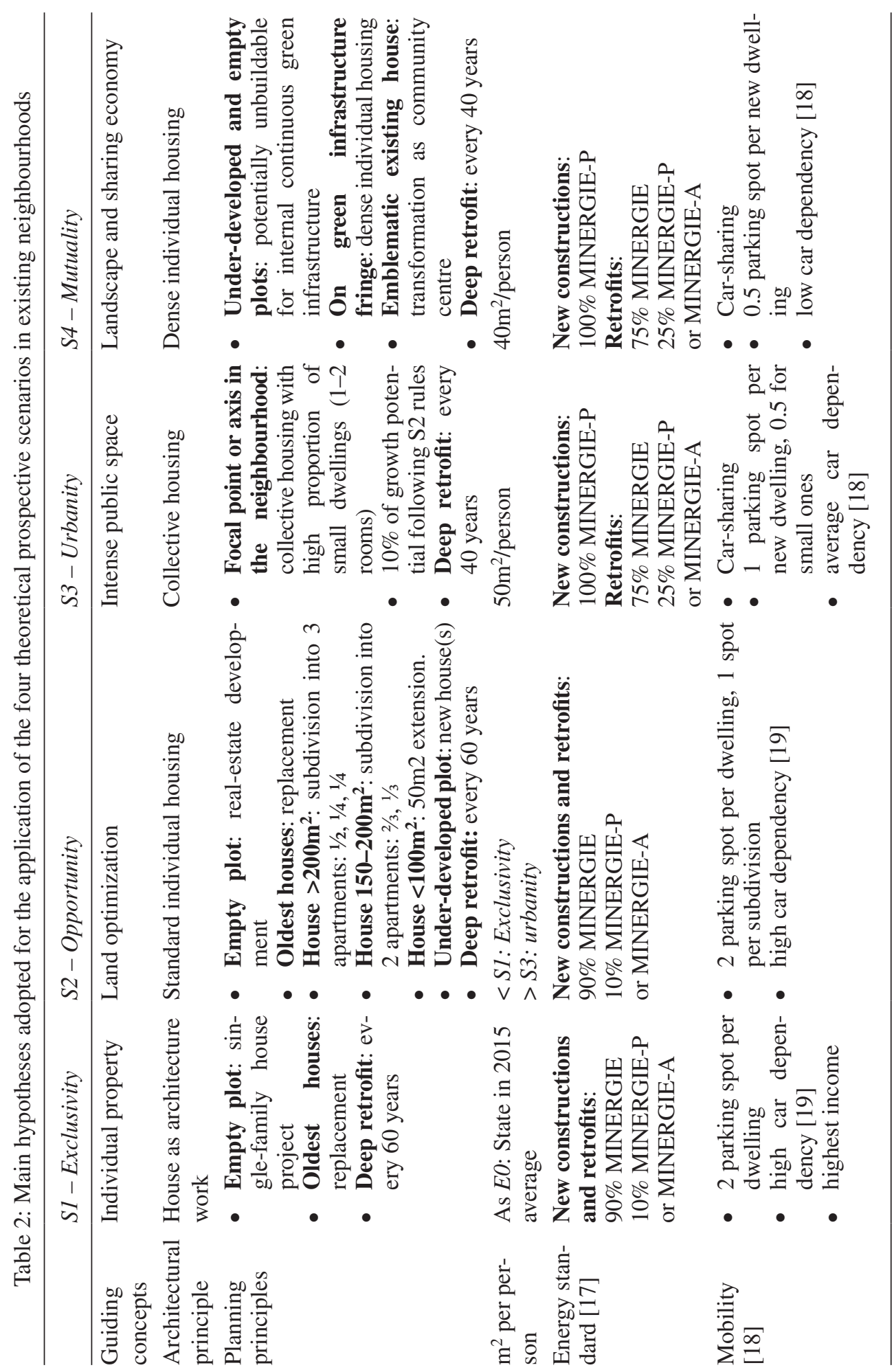


of the neighbourhood, supported by the creation of a high quality network of shared spaces in the form of streets and places or green infrastructure. $S 3$ focuses on developing a strategic sector of the neighbourhood. $S 4$ promotes social aspects of proximity, shared economy, etc. A set of rules and hypothesis presenting in Table 2, helps setting the conceptual framework of each scenario and orients the design decisions for their application in the case studies.

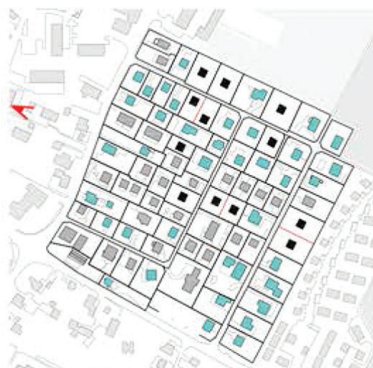

S1: Exclusivity

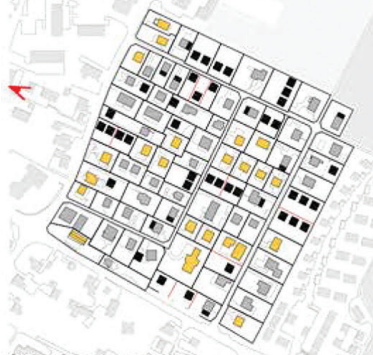

S2: Opportunity

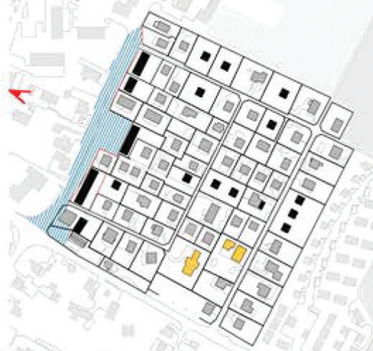

S3: Urbanity

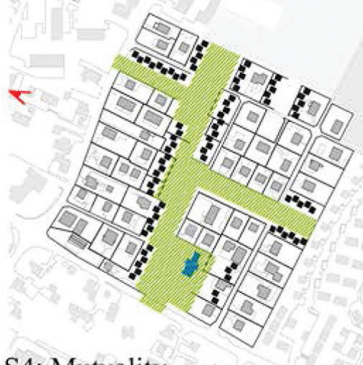

S4: Mutuality

$0 \mathrm{~m}$ $200 \mathrm{~m}$
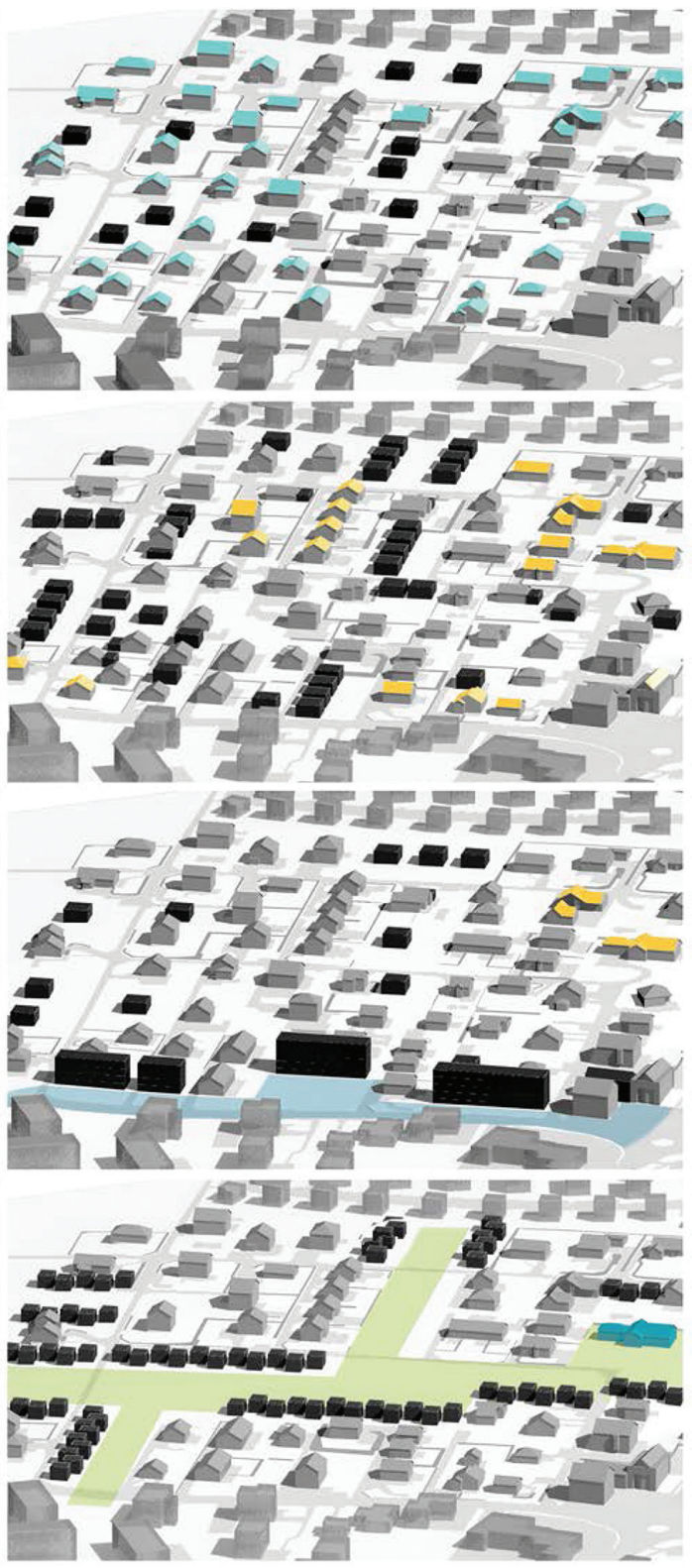

Figure 3: Test application of four scenarios in Chavornay. See figure 2 for caption. 


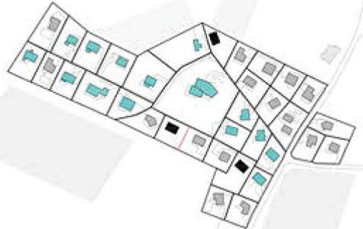

S1: Exclusivity

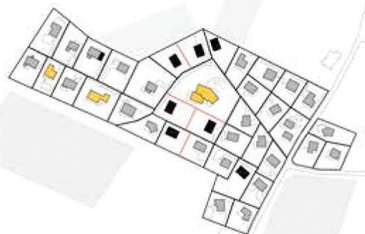

S2: Opportunity

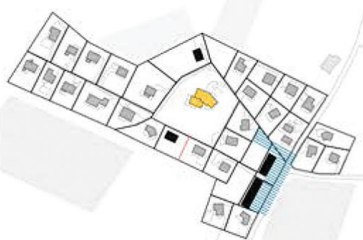

S3: Urbanity $\vee$

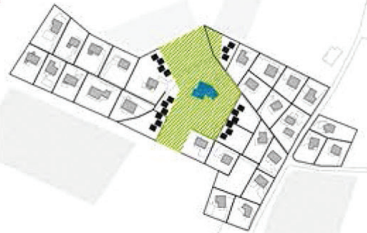

S4: Mutuality $\checkmark$

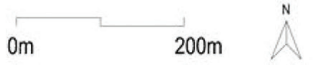

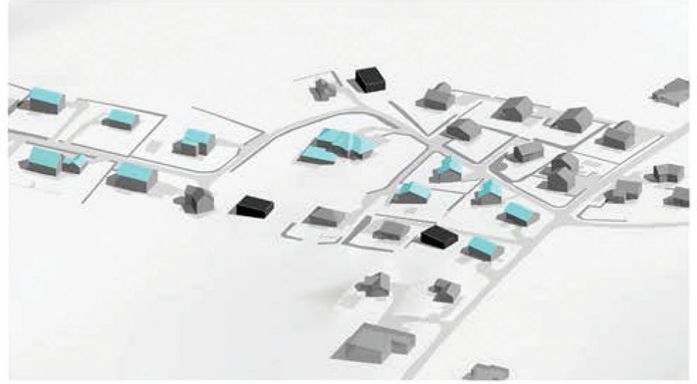
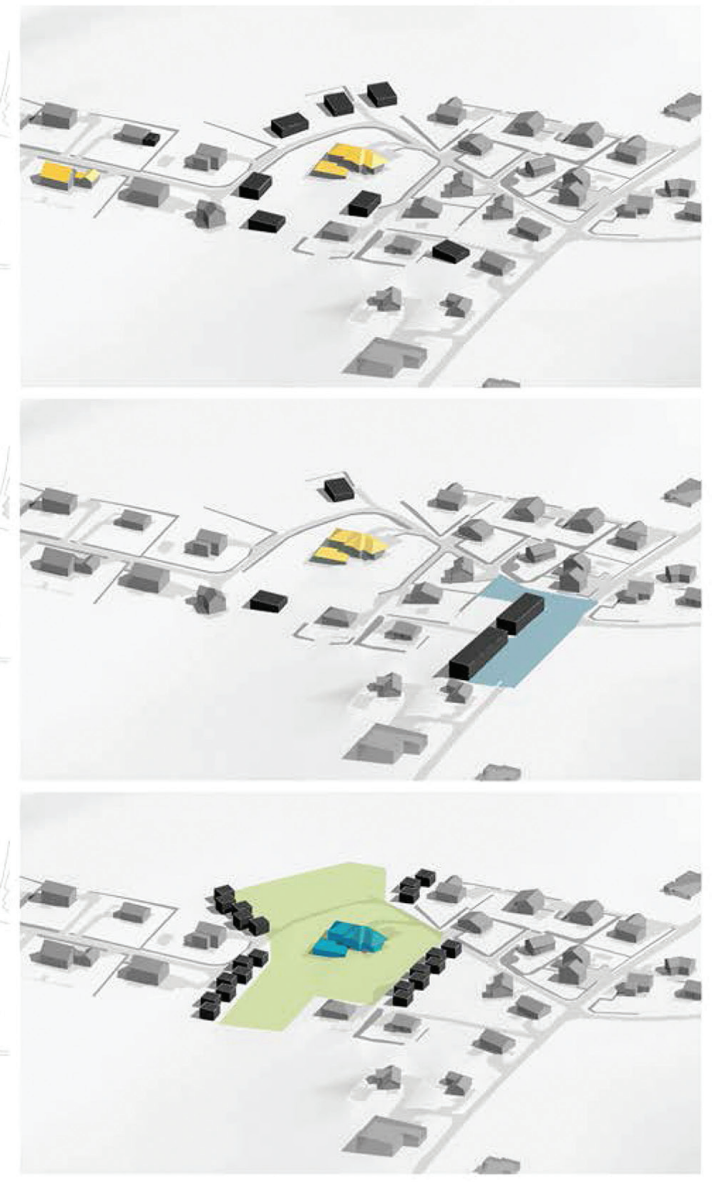

Figure 4: Test application of four scenarios in Savigny. See figure 2 for caption. 


\section{TEST-APPLICATION IN REAL CASE-STUDIES}

A leading aspect of the Living peripheries project is to compare and assess sustainability performances of the previously presented prospective scenarios for the evolution of periurban neighbourhoods of single-family houses by 2050 in Switzerland. One way of achieving this goal is by implementing the scenarios in real case studies to assess their effects in the scope of what allows the LTP. Figures 3 and 4 illustrate the urban and architectural design of the test-applications in Chavornay and Savigny, according to hypothesis listed in Table 2. They highlight the variable intensity of changes happening in each of the four prospective scenarios by 2050 .

\section{PRELIMINARY ASSESSMENT}

This section presents the preliminary assessment of the scenarios according to 5 indicators assessed at neighbourhood scale, using E0: State in 2015 as baseline and the "2'000-Watt society vision" targets as requirement for 2050 [20].

According to Fig. 5, demographic growth remains lower than limits established by the LTP for scenario S1: Exclusivity (CHA/SAV_S1). In scenarios S3: Urbanity (CHA/SAV_S3) and S4: Mutuality (CHA/SAV_S4), on the other hand, the growth potential allowed by the law conditions both the architectural scheduling and the future population. Regarding S2: Opportunity (CHA/SAV_S2), the effects of the law's regulation are notable. In the case of CHA_S2, all possible modifications can occur without limitation while in SAV_S2, the population threshold is reached with only few new buildings.

Figure 6 presents results related to land use and density. Figure $6 a$ highlights the modification resulting from each scenario. S1: Exclusivity and S2: Opportunity follow a similar guiding concept (Table 2) based on the permanence of private property and the singlefamily house model. However, S2: Opportunity exploits a growth potential about 3 times higher in CHA_S2/S1 (6'370 m²/1'980 m²), and about twice higher in the case of SAV_S2/ S1 $\left(1^{\prime} 050 \mathrm{~m}^{2} / 495 \mathrm{~m}^{2}\right)$. Results for S3: Urbanity and S4: Mutuality underline the effects of the neighbourhood planning which carries out many building substitutions.

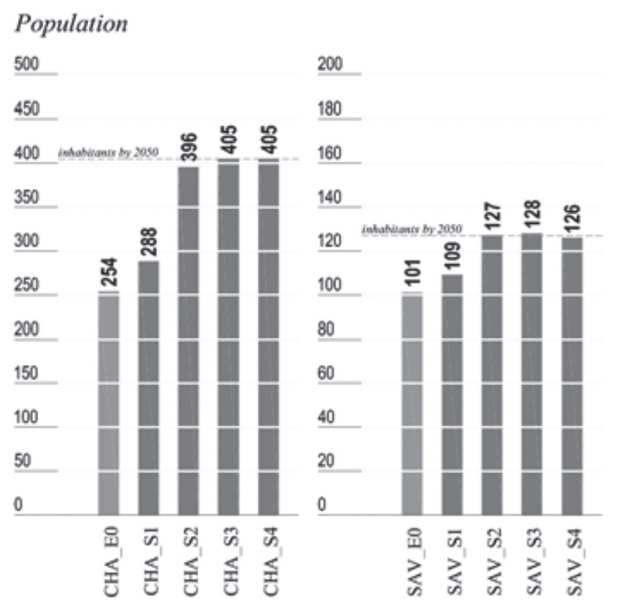

Figure 5: Neighbourhood population. 'Inhabitants by 2050' represents the threshold set by LTP's annual growth rate (Source: State of Vaud, 2016). 


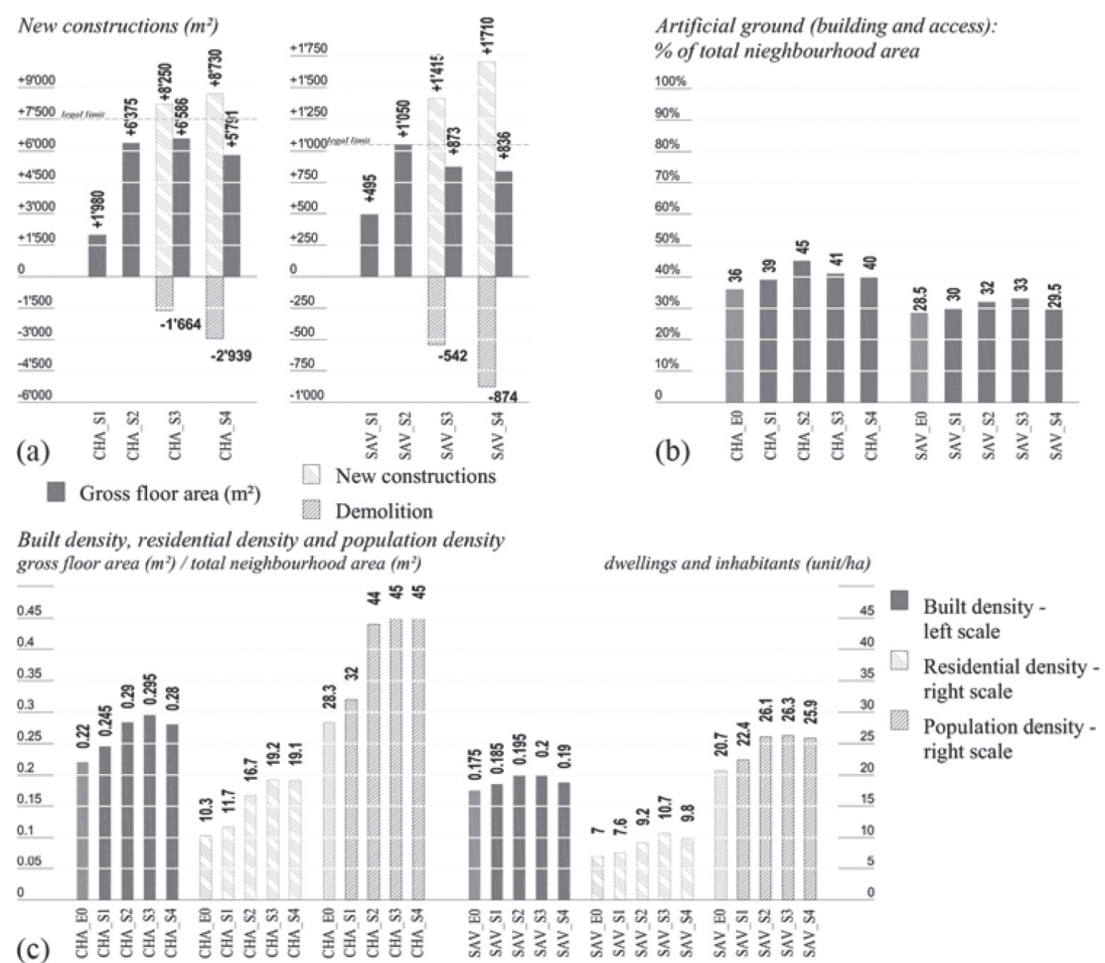

Figure 6: Land-use and density indictors. (a) Gross floor area balance. (b) Artificial ground ratio. (c) Density indicators.
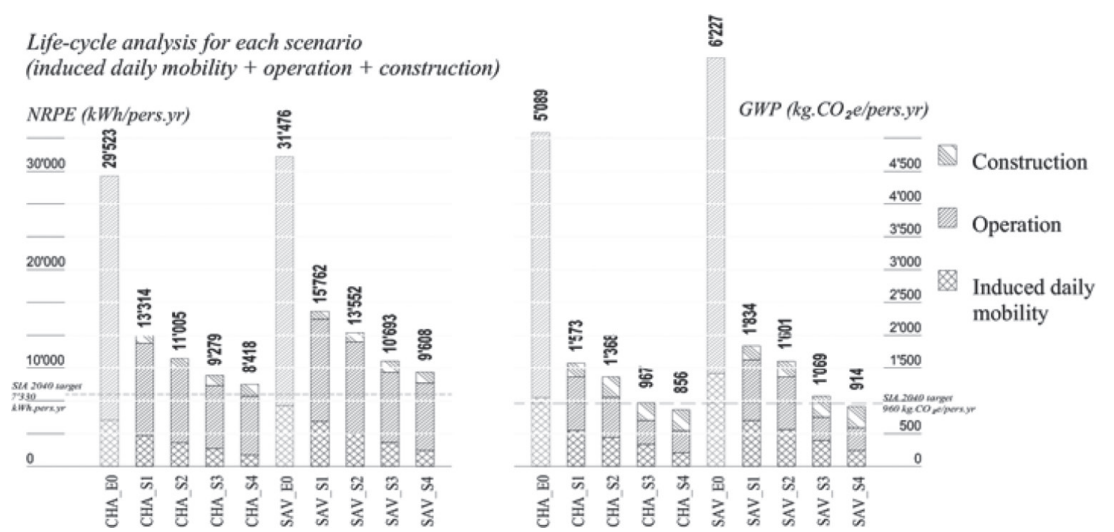

Figure 7: Life-cycle analysis per person per year in non-renewable primary energy demand (NRPE) and global warming potential (GWP). (Source: Drouilles et al., submitted).

Artificial ground ratio is an indicator of both land use and density (Fig. 6b). It shows a progressive increase of the artificial ground between E0: State in 2015 and CHA_S2/ SAV_S3, and a relative stagnation between S1: Exclusivity and S4: Mutuality. A transversal reading of Fig. $6 \mathrm{~b}$ and $\mathrm{c}$ shows a decorrelation of land use ratio and residential and population 
densities. S4: Mutuality achieves higher results on those aspects while preserving more soils. The reading of the built density plot highlights the living area reduction in S4: Mutuality thanks to smaller new dwellings (Table $2: \mathrm{m}^{2}$ per person).

Figure 8 presents a preliminary exploratory life-cycle analysis of each scenario. The assessment uses reference values (per $\mathrm{m}^{2}$ ) calculated following a bottom-up approach on four residential archetypes of the Swiss context [21]. The assessment assumes a retrofit cycle of 40 to 60 years and a more common recourse to energy efficient buildings (Table 2). Regarding the induced daily mobility, the assessment relies on the calculation method provided by [18], and assumes a progressive reduction of the car dependence [19]. It improves performances by 2.5 between S1: Exclusivity and S4: Mutuality. All four scenarios achieve a significant improvement by at least halving the energy demand and dividing the global warming potential (GWP) by 3.5. Results show the important weight of the operational energy demand and the significant impact of the construction phase in GWP. The demolition / new construction process has an overall positive effect on the neighbourhood's life cycle analysis, where S3: Urbanity and S4: Mutuality get closer to the requirements set for 2050 [20, 22].

\section{TOWARDS SUSTAINABLE TRANSITION PATHS?}

The question of the peri-urban residential neighbourhood renewal is at the margins of current trends in urban growth, being highly limited by LTP requirements that orient the majority of new developments in well-connected central areas. This on-going research project investigates the potential transition of existing peri-urban neighbourhoods of single-family houses towards sustainability by 2050 . Through a research by design process, the intermediate results presented in this paper provide some initial elements to improve the designs until they reach a higher level of detail.

These designs, although schematic, raise a significant amount of perspectives and open a wide range of questions. They highlight that, considering the constraining Swiss policy framework, sustainable transition paths for peri-urban neighbourhoods of single-family houses depend on an optimization of pre-existing built-areas more than on densification. Apart from scenario S1: Exclusivity, which reproduces the current land occupation, all other scenarios respect the prescribed growth potential. Current trends relying on soft-densification and illustrated through scenario S2: Opportunity show a higher dispersion of the transformations among the entire neighbourhood. Scenarios S3: Urbanity and S4: Mutuality on the other hand concentrate the evolutions in a designated area. Planning at neighbourhood scale results in more targeted transformations following a strong guiding concept, rather than private interests.

The preliminary assessment highlights that scenarios $S 2$ : Opportunity to S3: Urbanity and S4: Mutuality achieve similar results in terms of population, land use and density. Regarding the environmental impacts of dwelling use, the results raise the question of the existing stock inertia. Despite undertaking deep retrofit actions, dwellings still demand much energy due to a lasting dwelling under-occupation. In fact, despite new constructions and transformations, the built-area per person remains between $60 / 80 \mathrm{~m}^{2}$ whereas the LTP requires $50 \mathrm{~m}^{2}$.

A strengthened multicriteria assessment along with the comparison of (1) the effects of several scenarios applied in one neighbourhood and (2) the performances of one particular scenario among different neighbourhood types will allow identifying several conditions able to improve or worsen the sustainability transition potential of peri-urban neighbourhoods of single-family houses. The foreseen application and evaluation of the prospective scenarios to a higher level of detail for each category of the typology of peri-urban neighbourhoods of 
single-family houses (i.e. five case studies) will provide outputs that should support the expression of policy guidelines towards more sustainable peri-urban neighbourhoods and communities.

\section{ACKNOWLEDGEMENTS}

This research is supported by the Swiss National Science Foundation in the framework of the "Living Peripheries" project (Project n¹00013_152586/1).

\section{REFERENCES}

[1] Rey. E., (ed), Suburban polarity, Presses Polytechniques Universitaires Romandes, Lausanne, CH, 2017.

[2] Bosshard, M., Kurath, S., Luchsinger, C., Primas, U., Weiss, T., Helfenstein, H. \& Zürcher Hochschule für Angewandte Wissenschaften, (ed), Zukunft Einfamilienhaus?: Detached houses - the future? Niggli, Sulgen, CH, 2014.

[3] Swiss government. Loi fédérale sur l'aménagement du territoire (LAT). RO 1979 1573, Bern, CH, 2013.

[4] Drouilles, J., Lufkin, S. \& Rey, E., Peri-urban communities in transition: transformation scenarios of neighbourhoods towards sustainability, Proceedings of 33rd PLEA International conference: Design to Thrive, Network for comfort and energy use in buildings (NCEUB), Edinburgh, UK, pp. 4787-4794, 2017

[5] Drouilles, J., Lufkin, S. \& Rey, E., Towards a sustainable renewal of peri-urban neighbourhoods of single-family houses in Switzerland, Proceedings of the International Conference for Sustainable Design of the Built Environment 2017, London, UK, pp. 776-786, 2017.

[6] State of Vaud. 4e adaptation du plan directeur cantonal, Service du développement territorial, Lausanne, $\mathrm{CH}$, available at www.vd.ch/themes/territoire/amenagement/lat-revisee/4e-adaptation-du-plan-directeur-cantonal/ (accessed 18 October 2016)

[7] Moreau, A., Perspectives de population 2015-2040, Vaud et ses régions. Statistique Vaud, Lausanne, CH, 2016.

[8] Federal Statistical Office, L'espace à caractère urbain en Suisse en 2012, une nouvelle définition des agglomérations et d'autres catégories d'espace urbain, 1479-1200, Neuchâtel, CH, 2014.

[9] Gonçalves, J., Gomes, M.C., Ezequiel, S., Moreira, F. \& Loupa-Ramos, I., Differentiating peri-urban areas: a transdisciplinary approach towards a typology. Land Use Policy, 63, pp. 331-341, 2017. https://doi.org/10.1016/j.landusepol.2017.01.041

[10] E.E.A., The impacts of urban sprawl. In: Urban sprawl in Europe - The ignored challenge, Office for Official Publications of the European Communities, Luxembourg, 2006.

[11] Plan Construction, (ed), Typologie de l'habitat ancien 1850-1948, Abbaye de Royaumont, FR, 1979.

[12] Federal Office for Spatial Development, Niveaux de qualité de desserte par les transports publics, 2017, available at map.geo.admin.ch (accessed 01 Feburary 2018)

[13] Garnier, A., Les nouvelles cités dortoirs: l'expansion de la maison individuelle périurbaine, Presses polytechniques romandes, Lausanne, CH, 1984.

[14] Federal Statistical Office, Statistique de la population et des ménages STATPOP, 2015, available at www.pxweb.bfs.admin.ch (accessed 29 January 2018) 
[15] French National Research Agency, BIMBY: Build in my backyard, 2011, available at bimby.fr (accessed 01 February 2018)

[16] Beyeler, M., Métamorphouse: transformer sa maison au fil de la vie, Presses Polytechniques et Universitaires Romandes, Lausanne, CH, 2014.

[17] Minergie, Minergie - Home, 2017, available at www.minergie.ch (accessed 23 July 2017)

[18] Swiss Society of Engineers and Architects, SIA 2039: Mobilité: consommation énergétique des bâtiments en fonction de leur localisation, SIA, Zurich, CH, 2011.

[19] Federal Statistical Office \& Federal Office for Spatial Development. Comportement de la population en matière de transports: résultats du microrecensement mobilité et transports 2015. 841-1500, Neuchâtel, CH, pp. 12, 2017.

[20] Drouilles, J., Lufkin, S. \& Rey, E., Energy transition potential in peri-urban dwellings: assessment of theoretical scenarios in the Swiss context. Energy and Buildings, 148, pp. 379-390, 2017.

https://doi.org/10.1016/j.enbuild.2017.05.033

[21] Swiss Society of Engineers and Architects, SIA 2040: La voie SIA vers l'efficacité énergétique, SIA, Zurich, CH, 2011.

[22] Drouilles, J., Aguacil, S., Hoxha, E., Jusselme, T., Lufkin, S. \& Rey, E., Comparison scenarios of the life cycle analysis and the induced mobility of four residential building archetypes in the Swiss context, submitted. 